\title{
Disturbed calcium-vitamin D metabolism in patients on anti-epileptic drugs
}

\author{
Dabla PK ${ }^{*}$, Sharma $\mathrm{S}^{2}$ and Puri V ${ }^{3}$ \\ ${ }^{1}$ Department of Biochemistry, G.B Pant Institute of Postgraduate Medical Education \& Research, Associated to Maulana Azad Medical College, New Delhi, India \\ ${ }^{2}$ Department of Biochemistry, Chacha Nehru Bal Chikitsalya, Associated to Maulana Azad Medical College, New Delhi, India \\ ${ }^{3}$ Department of Neurology, G.B Pant Institute of Postgraduate Medical Education \& Research, Associated to Maulana Azad Medical College, New Delhi, India
}

\begin{abstract}
Introduction: Epilepsy is a common chronic neurological disorder, usually requiring long term treatment with anti-epileptic drugs (AEDs). There is paucity in data in relation to the effect of AED on calcium metabolism in North India. In view of this the present study was undertaken to assess the effect of AED on calcium metabolism.

Methods: The present cross-sectional study included epileptic patients of both sex attending the neurology OPD \& IPD clinics. Patients were divided into three groups: - group 1 included patients on monotherapy receiving $1 \mathrm{AED}$, group 2 on dual therapy receiving 2 AED and group 3 patients on polytherapy receiving 2 AED. Serum analysis of total calcium, phosphorus, alkaline phosphorus, ionised calcium \& vitamin D levels were conducted. The data between the groups was analyzed by using 1 way analysis of variance (ANOVA).

Results: The study included 150 patients in which 50 patients each belonged to groups1, 2 and 3 respectively. $60 \%$ patients were male. 86 patients had generalised epilepsy and 64 suffered from partial seizures. $42 \%$ of the patients were on AED treatment for $>5$ years. Serum levels of calcium and vitamin D were significantly decreased ( $p=.000$ and $p>0.05$ respectively) in the polytherapy group in comparison to the mono and dual therapy groups. On the other hand, alkaline phosphatase \& phosphorus levels were significantly increased in the polytherapy group $(\mathrm{p}=.000)$.
\end{abstract}

Conclusion: Hypovitaminosis was commonly observed in the patients on AED, even at sub-therapeutic serum levels of the drug.

\section{Introduction}

Epilepsy is a neurological disorder characterised by abnormal brain activity, causing seizures or periods of unusual behaviour, sensations and sometimes loss of awareness. The disease affects males and females of all races, ethnic background and ages. Transient symptoms can occur, such as loss of awareness or consciousness and disturbances of movement, sensation (including vision, hearing, and taste), mood, or mental function [1].70 million individuals are affected with epilepsy all over the world and nearly 12 million reside in India. The overall prevalence in India approximates 3 to 11.9 per 1000 population [2]. Anti epileptic drugs (AEDs) are the first choice of treatment for these individuals. However more than $50 \%$ of epileptics on AED develop bone abnormalities [3]. Cytochrome P-450 (CYP450) isoenzymes are induced by AEDs especially the classic AEDs such as benzodiazepines, cabamezepine, phenytoin, phenobarbital and valproic acid. The induction of these CYP-450 enzymes may lead to vitamin D deficiency, hypercalcemia, and increased risk of fractures, altered bone turnover which can lead to impaired bone mineral density [3]. Apart from AEDs, glucocorticoids, aromatase inhibitors, and anti-androgenic drugs are also associated with increased risk of osteoporosis [4]. If these drugs are used with AEDs, the risk of a decrease in bone density is highly increased. Recent studies have demonstrated that the awareness of neurologists regarding the effects of AEDs on bone density is low (28\%). It has been reported that a small number of pediatric neurologists (9\%) and adult neurologists (7\%) prophylactically prescribe calcium and vitamin $\mathrm{D}$ together with AEDs [5]. The negative effects of AEDs on bone density are complex, and their mechanism has not been fully understood. Both enzyme-inducing and non-inducing AEDs may cause abnormalities in bone metabolism [6,7]. There are very few studies in the Indian subcontinent evaluating vitamin $\mathrm{D}$ and calcium profile in epileptic patients with different treatment modalities. The aim of the present study was to therefore investigate the calcium metabolism in epilepsy patients who were on mono, dual and polytherapy anti-epileptic drug regime.

\section{Materials and methods}

The present cross-sectional study included consented epileptic patients of both sex attending the epilepsy clinic, admitted to the neurology ward of GIPMER New Delhi. It was conducted between period of Jan to Dec 2017. Patients with co morbid illness such as gastrointestinal disease, chronic liver disease, kidney disease or those on calcium-vitamin D supplementation were excluded from the study. Patients were divided into three groups: - group 1 included patients on monotherapy receiving $1 \mathrm{AED}$, group 2 on dual therapy receiving $2 \mathrm{AED}$

${ }^{\star}$ Correspondence to: Dr. Pradeep Kumar Dabla, MD , Professor, Department of Biochemistry, G.B Pant Institute of Postgraduate Medical Education and Research, Associated to Maulana Azad Medical College, New Delhi, India, E-mail: pradeep_dabla@gmail.com

Key words: anti-epileptic drugs, calcium metabolism, vitamin D, epilepsy

Received: December 23, 2019; Accepted: January 03, 2020; Published: January 06,2020 
and group 3 patients on polytherapy receiving $>2$ AED. 4-5 $\mathrm{ml}$ of blood sample was collected in plain red vacutainer under aseptic conditions for analysing total calcium, phosphorus, alkaline phosphorus, ionised calcium, Vitamin D and Parathyroid hormone (PTH) levels. Fresh, clear, and nonhemolyzed samples were used. Routine tests were analyzed by Roche Cobas c501 autoanalyzer. The serum was separated and stored at $-20^{\circ} \mathrm{C}$ until batch analysis for the estimation of $25(\mathrm{OH})$ hydroxyvitamin D $(25(\mathrm{OH})$ D), PTH with Roche immunoassay autoanalyzer Cobas e411 using electrochemiluminescence technique. The minimum detection limit for PTH was $1 \mathrm{pg} / \mathrm{ml}$ (reporting reference interval $15-65 \mathrm{pg} / \mathrm{ml}$ ) and for $25(\mathrm{OH}) \mathrm{D}$ was $5 \mathrm{ng} / \mathrm{ml}$ with the analytical measurement range of 3-70 ng/ml. The preferred level for $25(\mathrm{OH}) \mathrm{D}$ is recommended to be $\geq 30 \mathrm{ng} / \mathrm{ml}$. In this protocol, vitamin D deficiency was defined by serum levels of $25(\mathrm{OH}) \mathrm{D}<20 \mathrm{ng} / \mathrm{ml}$. Insufficiency was defined as $25(\mathrm{OH}) \mathrm{D}$ between 20 and $30 \mathrm{ng} / \mathrm{ml}$. Data was expressed as mean \pm standard deviation values. The data between the groups was analyzed by using 1-way analysis of variance (ANOVA). A p value of $<0.05$ was accepted as statistically significant.

\section{Results}

The present cross-sectional study included 150 patients in which 50 patients each belonged to groups 1, 2 and 3 respectively. Patients in our study were associated with age group of 15-35 years with male:female ratio of 1.4:1. Mean age of onset of seizures in the study group was $19.18 \pm 7.43$ yrs. 86 patients had generalised epilepsy and 64 suffered from partial seizures. Table 1 shows $42 \%$ of the patients were on AED treatment with seizures duration for more than 5 years whereas the mean duration of seizures was highest in polytherapy group as $5.86 \pm 2.31$ years in Table 4 . With reference to Table 2 showing biochemical measurements, calcium and phosphorus levels were found to be significantly decreased in patients on polytherapy in comparison to those on mono and dual therapy ( $\mathrm{p}=0.000$ respectively). Similarly, Vitamin D levels were found to be the lowest in patients on polytherapy ( $\mathrm{p}=0.000$ ). On the other hand, levels of Alkaline Phosphatase \& PTH were found to be elevated in the polytherapy group $(\mathrm{p}=0.000)$ as shown in Table 2 .

$25(\mathrm{OH})$ Vitamin D deficiency $(<20 \mathrm{ng} / \mathrm{mL})$ was observed in $72 \%$ patients on monotherapy $(n=36)$, in $86 \%$ patients on dual therapy $(n=43)$ and $96 \%$ patients on polytherapy $(n=48)$ as shown in Table 3. On correlating serum levels of Vitamin D with duration of seizures a negative correlation was observed in all patients though the correlation was found to be statistically significant in polytherapy group $(\mathrm{p}<0.05)$ as shown in Table 4.

\section{Discussion}

Epilepsy is a major public health problem affecting majority of people worldwide. Treatment with AEDs is generally chronic, if not lifelong and may be associated with significant metabolic effects including decreased bone mass and increased fractures [8,9]. This

Table 1. Demographic characteristics of patient's according to the type of therapy

\begin{tabular}{|l|c|c|c|}
\hline $\begin{array}{l}\text { Demographic } \\
\text { characteristics }\end{array}$ & $\begin{array}{c}\text { Patients on mono } \\
\text { therapy }\end{array}$ & $\begin{array}{c}\text { Patients on dual } \\
\text { therapy }\end{array}$ & $\begin{array}{c}\text { Patients on poly } \\
\text { therapy }\end{array}$ \\
\hline Mean age & $23.58 \pm 8.5$ & $23.6 \pm 8.6$ & $25.1 \pm 11.7$ \\
\hline Male/Female & $25 / 25$ & $32 / 18$ & $31 / 19$ \\
\hline Duration of seizure & & & \\
$<5$ yrs & 36 & 35 & 18 \\
\hline $5-10$ yrs & 14 & 11 & 30 \\
$>10$ yrs & 0 & 4 & 2 \\
\hline Mean age of onset & $19.44 \pm 6.8$ & $18.88 \pm 6.10$ & $19.22 \pm 10.9$ \\
\hline
\end{tabular}

Table 2. Laboratory characteristics of patient's according to the type of therapy. ${ }^{*} \mathrm{p}=0.000$

\begin{tabular}{|l|c|c|c|}
\hline Parameters & $\begin{array}{c}\text { Patients on mono } \\
\text { therapy }\end{array}$ & $\begin{array}{c}\text { Patients on dual } \\
\text { therapy }\end{array}$ & $\begin{array}{c}\text { Patients on poly } \\
\text { therapy }\end{array}$ \\
\hline S.Albumin & $4.5 \pm 0.26$ & $4.42 \pm 0.28$ & $4.49 \pm 0.23$ \\
\hline S.Calcium & $9.2 \pm 0.42$ & $8.9 \pm 0.31$ & $8.0 \pm 0.22^{*}$ \\
\hline S.Phosphorus & $4.46 \pm 0.96$ & $4.47 \pm 0.68$ & $4.26 \pm 0.43^{*}$ \\
\hline Alkaline Phosphatase & $109.3 \pm 22.4$ & $121.9 \pm 13.3$ & $149.2 \pm 18.6^{*}$ \\
\hline I. Ca ++ & $1.04 \pm 0.13$ & $1.03 \pm 0.12$ & $1.02 \pm 0.11$ \\
\hline PTH & $27.2 \pm 40.0$ & $48.53 \pm 18.9$ & $72.69 \pm 6.93^{*}$ \\
\hline Vitamin D & $16.81 \pm 6.34$ & $14.98 \pm 4.79$ & $10.66 \pm 4.65^{*}$ \\
\hline
\end{tabular}

Table 3. Vitamin D status of patient's according to the type of therapy

\begin{tabular}{|l|c|c|c|}
\hline Drug therapy & $\begin{array}{c}\text { No. (\%) of } \\
\text { patients with 25 } \\
\text { (OH) vitamin D } \\
\text { deficiency }\end{array}$ & $\begin{array}{c}\text { No. (\%) of } \\
\text { patients with 25 } \\
\text { (OH) vitamin D } \\
\text { insufficiency }\end{array}$ & $\begin{array}{c}\text { No. (\%) of } \\
\text { patients with 25 } \\
\text { (OH) vitamin D } \\
\text { sufficiency }\end{array}$ \\
\hline Patients on mono therapy & $36(72)$ & $13(26)$ & $1(2)$ \\
\hline Patients on dual therapy & $43(86)$ & $7(14)$ & $0(0)$ \\
\hline Patients on poly therapy & $48(96)$ & $2(4)$ & $0(0)$ \\
\hline
\end{tabular}

Table 4. Correlation of vitamin D levels with duration of seizure in different therapy groups

\begin{tabular}{|c|c|c|c|}
\hline Therapy & $\begin{array}{c}\text { Mean duration of } \\
\text { seizures }\end{array}$ & r value & p value \\
\hline Mono therapy & $3.85 \pm 2.24$ & -0.167 & 0.246 \\
\hline Dual therapy & $4.72 \pm 3.47$ & -0.155 & 0.282 \\
\hline Poly therapy & $5.86 \pm 2.31$ & -0.299 & $\mathbf{0 . 0 3 4}$ \\
\hline
\end{tabular}

is the first study to the best of our knowledge from northern India which looked into changes of bone metabolic parameters in patients who were on different regimens of antiepileptic drug therapy. Amongst users of AEDs, we observed significant hypocalcemia, hypoproteinemia, hyperparathyroidism, and increased levels of serum alkaline phosphatase in patients belonging to polytherapy group when compared to those on mono or dual therapy. Several theories have been proposed to explain the link between AEDs and bone disease. Hepatic induction of the cytochrome P450 enzyme system leading to increased catabolism of Vitamin D is the principal mechanism reported [10]. Other possible mechanisms include a direct effect on bone cells including impaired absorption of calcium and inhibition of response to $\mathrm{PTH}$, hyperparathyroidism, and calcitonin deficiency [11]. AEDs that induce hepatic cytochrome P450 enzymes may cause increased conversion of Vitamin D to polar inactive metabolites in the liver microsomes and reduce levels of bio-available Vitamin D. Decreased biologically active Vitamin D leads to decreased absorption of calcium in the gut, resulting in hypocalcemia, and an increase in circulating PTH, which increases the mobilization of bone calcium stores and subsequent bone turnover. AEDs may interfere with intestinal absorption of calcium. Impaired absorption would lead to hypocalcemia and feedback hypersecretion of PTH. Markedly decreased calcium absorption was found in rats treated with phenytoin but not with phenobarbitone ${ }^{11}$. Hyperparathyroidism also has been suggested as a possible mechanism. Hyperparathyroidism can primarily activate bone resorption and through a coupling phenomenon and secondarily activate bone formation. A final postulated mechanism is calcitonin deficiency. Calcitonin is a hormone produced by the thyroid gland that inhibits osteoclast mediated bone resorption. Calcitonin deficiency may, therefore, accelerate bone turnover. This deficiency has been demonstrated both in vitro and in vivo $[12,13]$. As $25(\mathrm{OH}) \mathrm{D}$ deficiency is very common in the general population, it is difficult to demonstrate that AED use specifically plays a role in the Vitamin D deficiency. In a study by Menon, it was observed that serum 25(OH) D levels declined from $29 \pm 1.3$ to $17.2 \pm 1.6 \mathrm{ng} / \mathrm{ml}(\mathrm{P}<0.001)$ within 6 months of initiation 
of AED therapy [14]. In another study by Krishnamurthy et al. It was observed that serum biochemical changes which may predispose the subjects to development of osteomalacia appear within 3 months of starting AED monotherapy. It suggested that simultaneous coadministration of calcium and $25(\mathrm{OH}) \mathrm{D}$ in recommended daily allowance dosage could be useful in limiting the changes in calcium and Vitamin D metabolism in patients on AEDs [15]. According to a study by Bartl et al. patients on long term treatment with AEDs have 2-3 fold risk of sustaining fractures. On an average, $50 \%$ of patients (ranging from $4 \%$ to $70 \%$ in different studies) have osteopathy. Bone loss has been noted with or even without evidence of Vitamin D deficiency among the enzyme-inducing drugs, especially phenytoin, phenobarbitone and carbamazepine [16].

We view the high prevalence of inadequate Vitamin D levels in epileptic patients as significant. Patients on polytherapy type of AED regimen are at a higher risk for low $25(\mathrm{OH})$ D levels. Virtually all epileptic patients are at a risk for hypovitaminosis $\mathrm{D}$. We could not screen our subjects with dual energy x-ray absorptiometry scans to evaluate bone mineral density. Therefore, we cannot comment on the impact of our patient's low Vitamin D levels on their bone mineralisation. However, we postulate that $25(\mathrm{OH})$ D levels are associated with abnormal bone metabolism and the risk for poor bone health and increased fracture risk.

\section{Conclusion}

The present study emphasizes the need to create bone health awareness amongst epileptic patients and health care providers. Proper counselling regarding calcium and vitamin D intake, exposure to sunlight and physical activity is required. Further studies are needed to formulate clear guidelines on prophylactic Vitamin D supplementation needed for prevention and treatment of impaired bone metabolism in epilepsy.

\section{Conflicts of interest}

None

\section{References}

1. WHO (2001) Epilepsy: Aetiogy, Epidemiology and Prognosis. Fact Sheet $\mathrm{N}^{\circ} 165$; February, 2001. Available from: http://www.idealibrary.com. [Last accessed date 2018 Jun 21].
2. Amudhan S, Gururaj G, Satishchandra P (2015) Epilepsy in India I: Epidemiology and public health. Ann Indian Acad Neurol 18: 263-277.

3. Fan HC, Lee HS, Chang KP, Lee YY, Lai HC, Hung PL et al. (2016) The Impact of Anti-Epileptic Drugs on Growth and Bone Metabolism. International journal of molecular sciences 17: 1242.

4. Lippuner K, Johansson H, Kanis JA, Rizzoli R (2009) Remaining lifetime and absolute 10 -year probabilities of osteoporotic fracture in Swiss men and women. Osteoporos Int 20: 1131-1140.

5. Valmadrid C, Voorhees C, Litt B, Schneyer CR (2001) Practice patterns of neurologists regarding bone and mineral effects of antiepileptic drug therapy. Arch Neurol 58: 1369 1374.

6. Boluk A, Guzelipek M, Savli H, Temel I, Ozişik HI, Kaygusuz A, et al. (2004) The effect of valproate on bone mineral density in adult epileptic patients. Pharmacol Res 50: 93-97.

7. Pack AM, Olarte LS, Morrell MJ, Flaster E, Resor SR, Shane E, et al. (2003) Bone mineral density in an outpatient population receiving enzyme inducing antiepileptic drugs. Epilepsy Behav 4: 169-174.

8. Sheth RD (2004) Metabolic concerns associated with antiepileptic medications. Neurology 63: S24- S29.

9. Pack AM, Gidal B, Vazquez B (2004) Bone disease associated with antiepileptic drugs. Cleve Clin J Med 71: S42-S48.

10. Pack AM, Morrell MJ (2001) Adverse effects of antiepileptic drugs on bone structure: Epidemiology, mechanisms and therapeutic implications. CNS Drugs 15: 633-642.

11. Koch HU, Kraft D, von Herrath D, Schaefer K (1972) Influence of diphenylhydantoin and phenobarbital on intestinal calcium transport in the rat. Epilepsia 13: 829-834.

12. Vernillo AT, Rifkin BR, Hauschka PV (1990) Phenytoin affects osteocalcin secretion from osteoblastic rat osteosarcoma 17/2.8 cells in culture. Bone 11: 309-312.

13. Kruse K, Suss A, Busse M, Schneider P (1987) Monomeric serum calcitonin and bone turnover during anticonvulsant treatment and in congenital hypothyroidism. J Pediatr 111: 57-63.

14. Menon B, Harinarayan CV (2010) The effect of anti-epileptic drug therapy on serum $25(\mathrm{OH})$ hydroxyvitamin $\mathrm{D}$ and parameters of calcium and bone metabolism - A longitudinal study. Seizure 19: 153-158.

15. Krishnamoorthy G, Nair R, Sundar U, Kini P, Shrivastava M (2010) Early predisposition to osteomalacia in Indian adults on phenytoin or valproate monotherapy and effective prophylaxis by simultaneous supplementation with calcium and $25(\mathrm{OH})$ hydroxy vitamin $\mathrm{D}$ at recommended daily allowance dosage: A prospective study. Neurol India 58: 213-219.

16. Bartl R (2007) Antiepileptic drug-induced osteopathy. Subtypes, pathogenesis,prevention, early diagnosis and treatment. Dtsch Med Wochenschr 132: 1475-1479.

Copyright: (C2020 Dabla PK. This is an open-access article distributed under the terms of the Creative Commons Attribution License, which permits unrestricted use, distribution, and reproduction in any medium, provided the original author and source are credited. 